\title{
Assessing interaction between dexmedetomidine and propofol
}

\author{
Gui-Zhen Yang ${ }^{1}$ Fu-Shan Xue ${ }^{1} \cdot$ Chao Sun $^{1}$
}

Received: 22 September 2016 / Accepted: 24 September 2016 / Published online: 17 October 2016

(C) Japanese Society of Anesthesiologists 2016

\section{To the Editor:}

In the recent article by Yoo et al. [1] assessing the effect of dexmedetomidine pretreatment on the median effective bolus dose of propofol for facilitating laryngeal mask airway insertion, dexmedetomidine $1 \mu \mathrm{g} / \mathrm{kg}$ was infused over $10 \mathrm{~min}$, followed by propofol $2.5 \mathrm{mg} / \mathrm{kg}$ administration and the laryngeal mask airway was inserted. The main disadvantage of using dexmedetomidine as a drug of anesthesia induction is slow onset. Because intravenous administration of dexmedetomidine has an onset of action after approximately $15 \mathrm{~min}$ in healthy adults, it is recommended that a single dose dexmedetomidine should be given $15 \mathrm{~min}$ before anesthesia induction [2]. Moreover, in the methods, there was no mention of time to start the laryngeal mask airway insertion after completion of propofol administration. After intravenous injection of propofol, the time to reach peak effect is about 100-120 s [3].

It must be emphasized that when anesthesia induction is performed with dexmedetomidine and propofol, clinicians should use the two drugs in such a way that their peak effects appear at the same time, acquiring most effective sedation and analgesia for subsequent airway procedure. We believe that a different median effective bolus dose of propofol for facilitating the laryngeal mask airway insertion would have been obtained if such an optimal drug administration planning was used in this study.

\section{Compliance with ethical standards}

Conflict of interest All authors have no financial support and potential conflicts of interest for this work.

\section{References}

1. Yoo JY, Kwak HJ, Kim YB, Park CK, Lee SY, Kim JY. The effect of dexmedetomidine pretreatment on the median effective bolus dose of propofol for facilitating laryngeal mask airway insertion. J Anesth. 2016. doi:10.1007/s00540-016-2245-7.

2. Afonso J, Reis F. Dexmedetomidine: current role in anesthesia and intensive care. Rev Bras Anestesiol. 2012;62:118-33.

3. Rolly G, Versichelen L, Huyghe L, Mungroop H. Effect of speed of injection on induction of anaesthesia using propofol. Br J Anaesth. 1985;57:743-6.

This comment refers to the article available at doi:10.1007/ s00540-016-2245-7.

Fu-Shan Xue xuefushan@aliyun.com

1 Department of Anesthesiology, Plastic Surgery Hospital, Chinese Academy of Medical Sciences and Peking Union Medical College, 33 Ba-Da-Chu Road, Shi-Jing-Shan District, Beijing 100144, People's Republic of China 